\title{
شعرية القصة الشاعرة
}

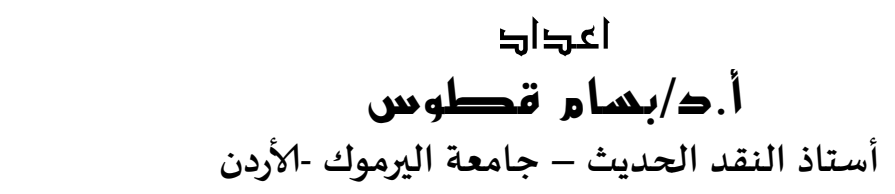

Doi: 10.12816/mdad.2019.48360

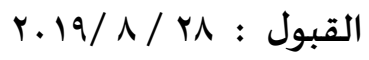

r.19/V/ع: : الاستلام

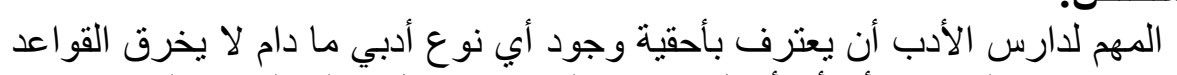

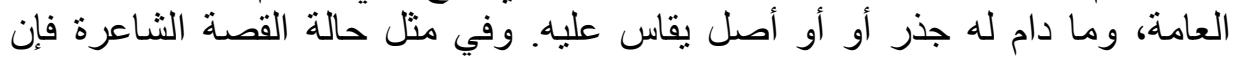

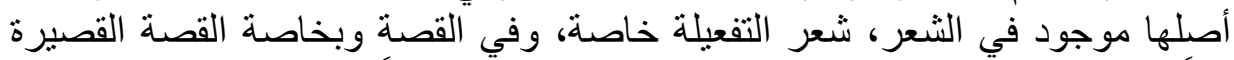

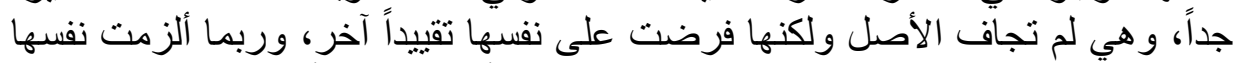

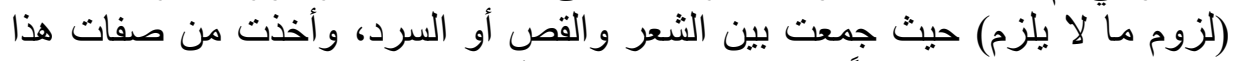

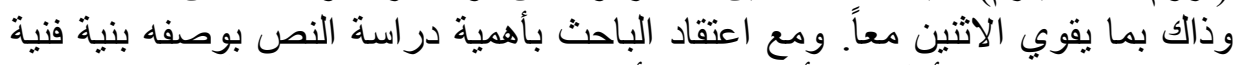

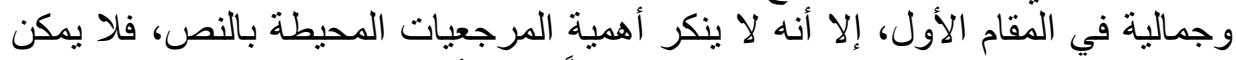

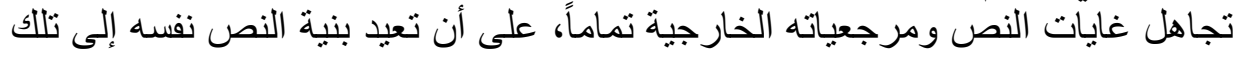

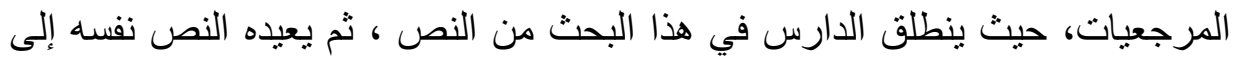

\section{Abstract:}

المرجعيات التي تضيء عنمتهن.

It is important for the student of literature to recognize the right to the existence of any type of literature as long as it does not violate the general rules, and as long as it has a root or origin measured on it. In the case of the Alkessa alshaera, its origin is in poetry, the poetry of activation in particular, and in the story, especially the very short story. Or narrative, and I took the qualities of this and that strengthens both. While the researcher believes the importance of studying the text as a technical and aesthetic structure in the first place, but does not deny the importance of references surrounding the text, can not ignore the goals of the text and external references completely, provided that the structure of 
the text itself to those references, The student in this search of the text, then returns the text itself to the references that illuminate its opacity.

لم أثأ أن أناقش في هذا البحث شرعية القصة الثاعرة، أو التأصيل لها؛ فهي

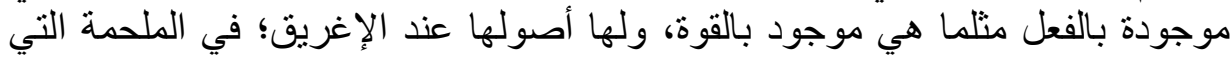

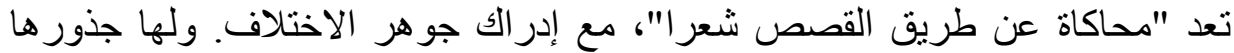

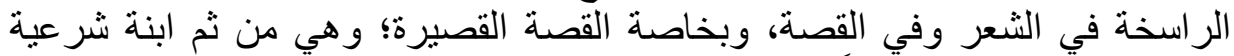

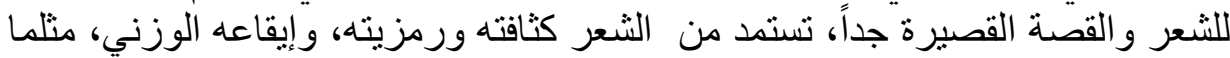

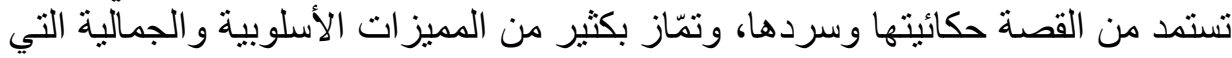
ستقف على بعضها هذه الونة الورقة

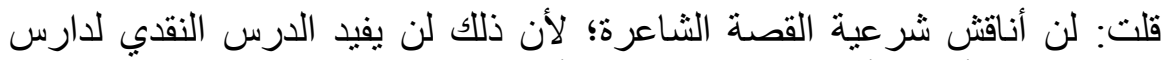

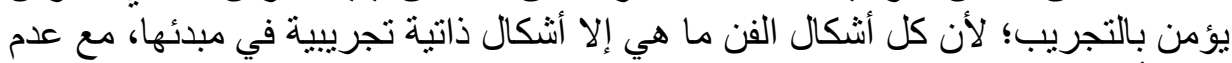

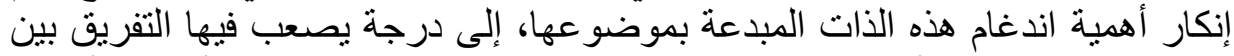

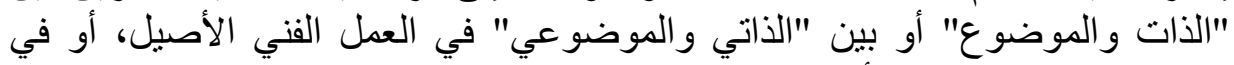
النماذج الفنية الخالدة التي أثبتت جمالثها عبر السنين.

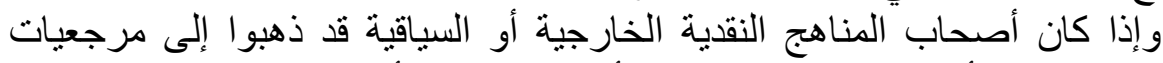

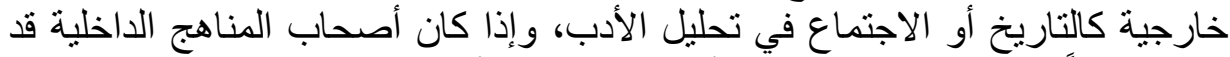

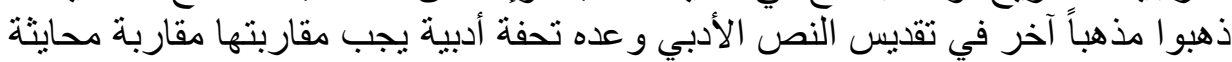

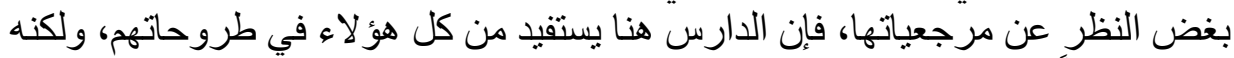

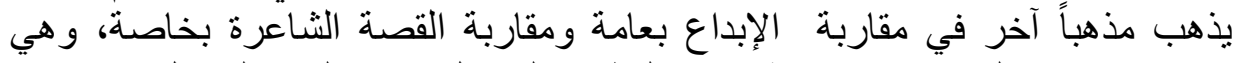

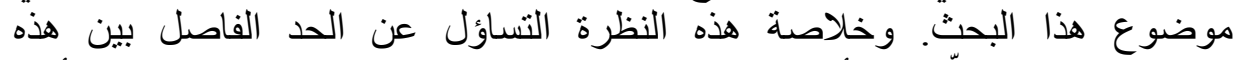

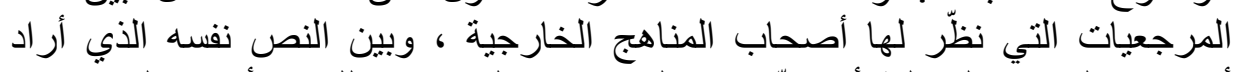

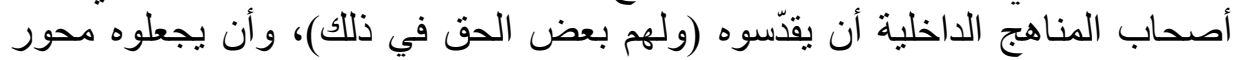

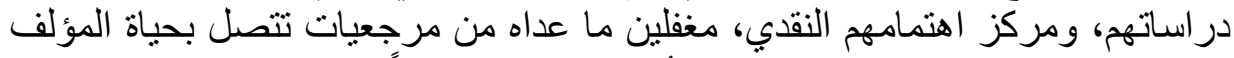

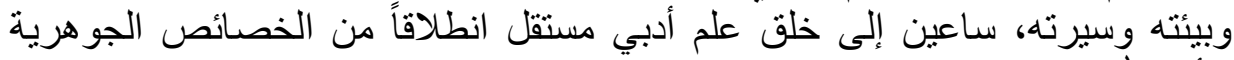
لنأدب. '

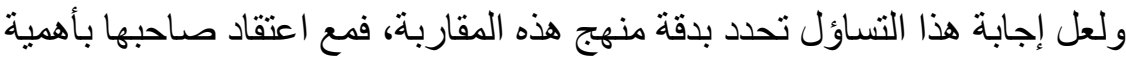

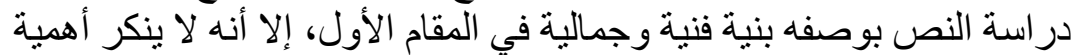

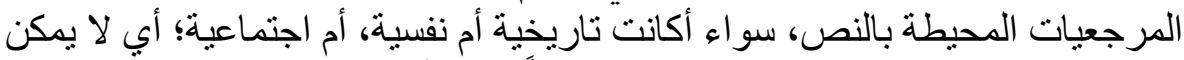

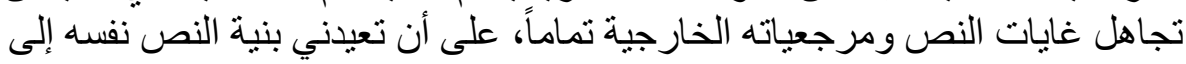

انظر :قطوس،دليل النظرية النقدية المعاصرة، الكويت، دار العروبة،صولاص 
تللك المرجعيات، فيكون النص هو المركز أو هو نقطة البدء و المعاد،الذي ينطلق منه النه

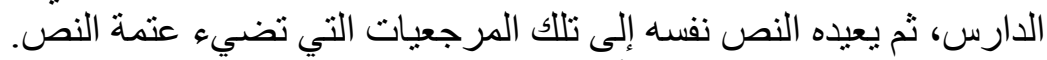

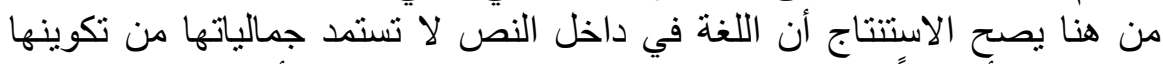

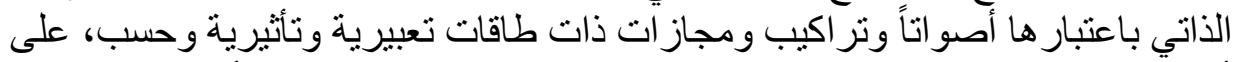

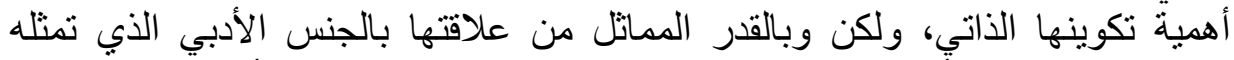

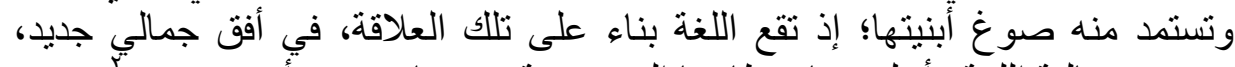
وتتحدد جمالية اللغة و أسلوبيتها بوظائفها التصويرية في سياق جنس أنساء أنبي محدد.

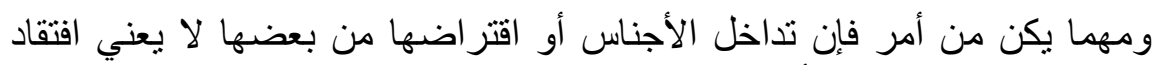

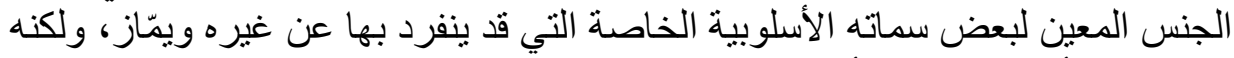

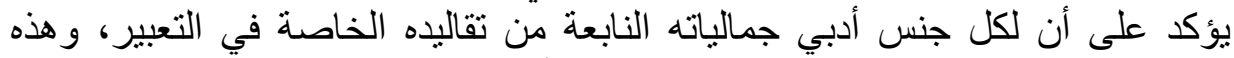

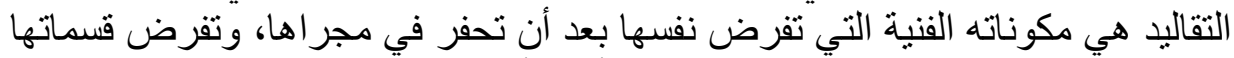

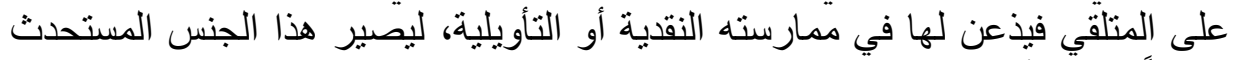

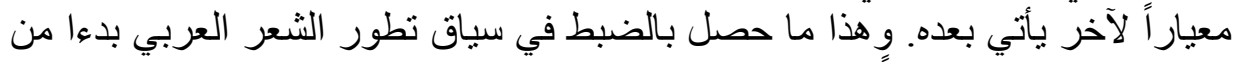

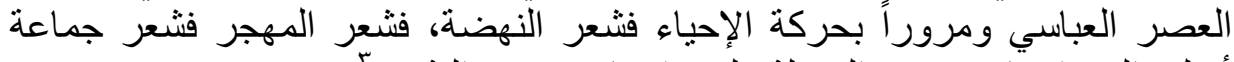

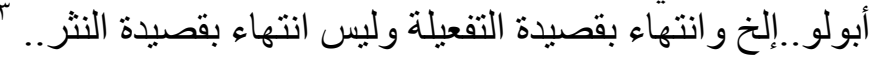

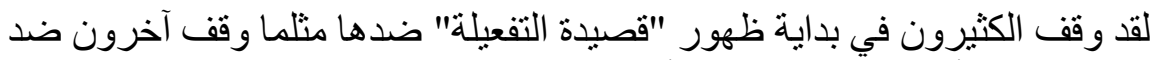

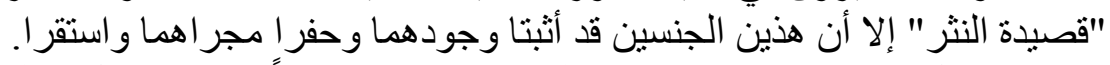

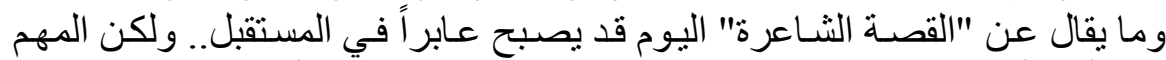

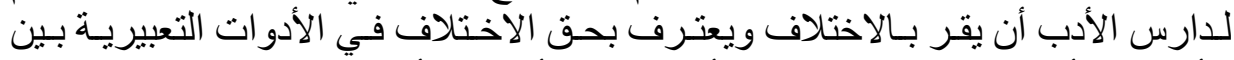

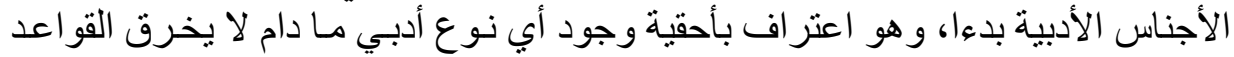

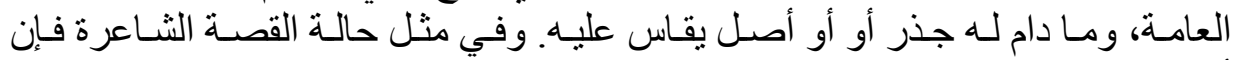

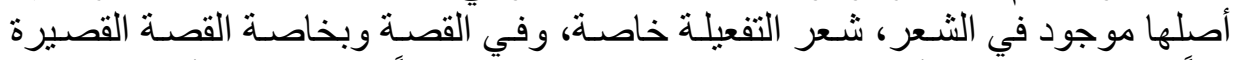

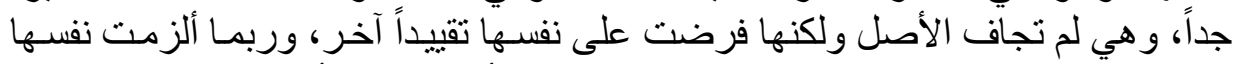

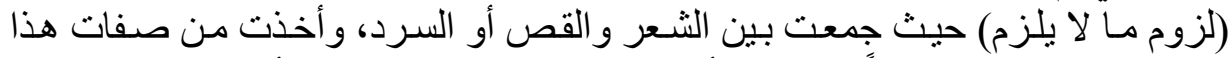

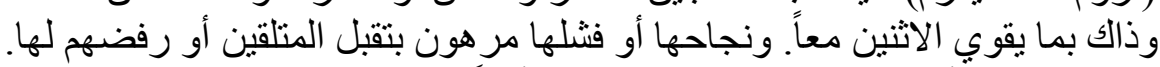

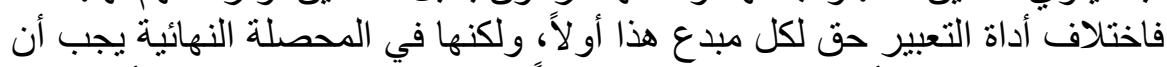

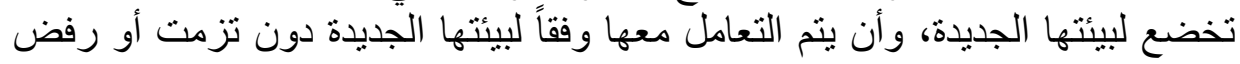

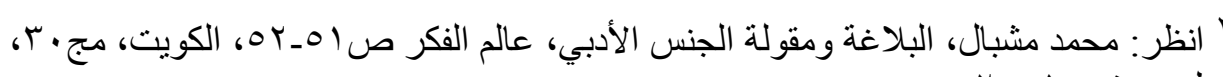

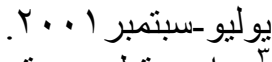
راجع قطوس، قصبيدة النثر:قراءة في انساق انساق النص وانسجام الخطاب مجلة مؤتة للبحوث 


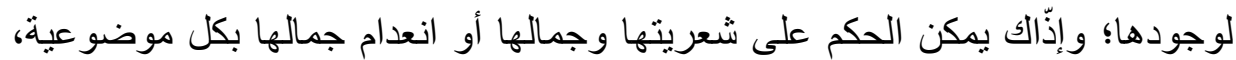

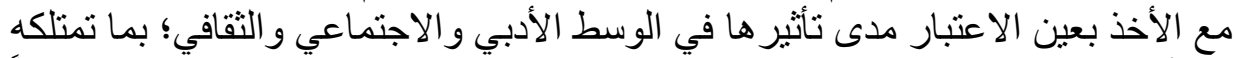

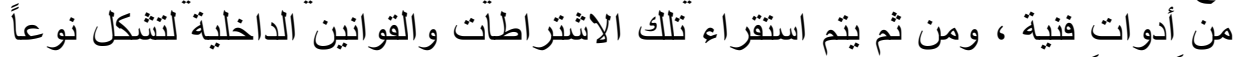
أدبياً جديداً. في مفهوم الثعرية:

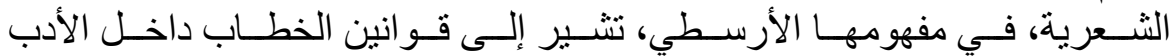

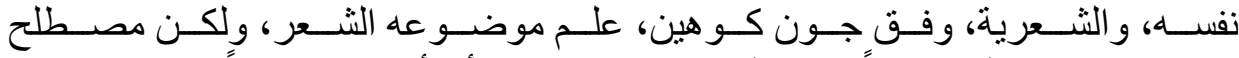

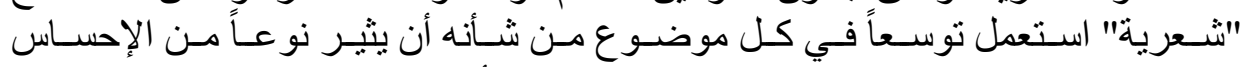

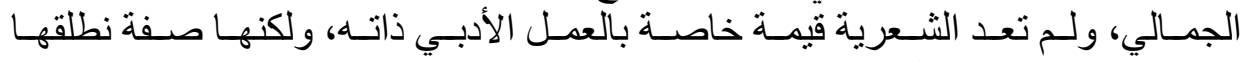

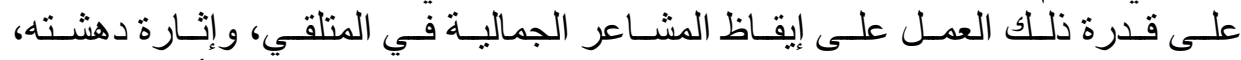

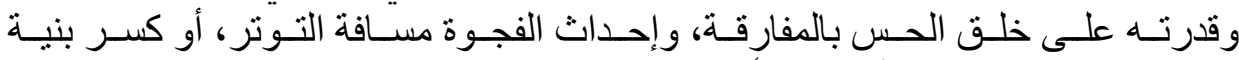
التوقع..إلخ من الملامح الأسلوبية.

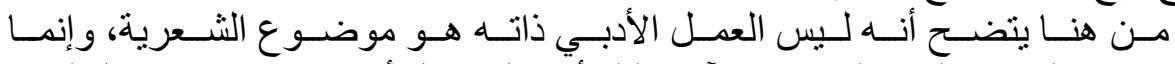

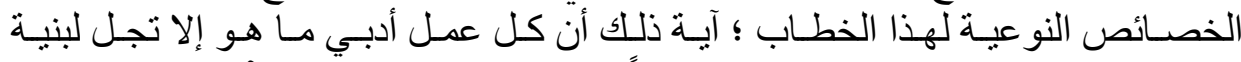

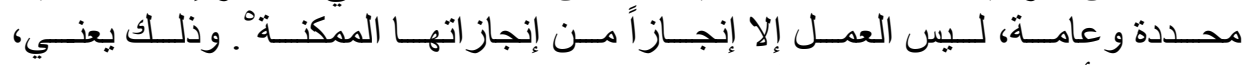

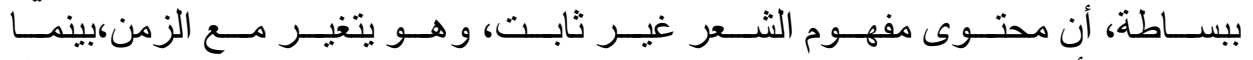

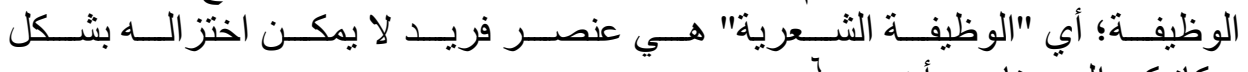
ميكانيكي إلى عناصر أخرى.

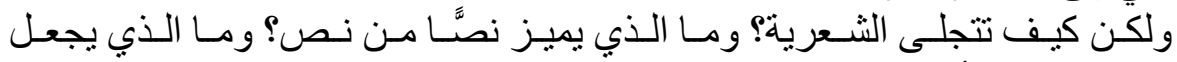

من نص ما يستحق أن يوصف بأب الشعرية؟

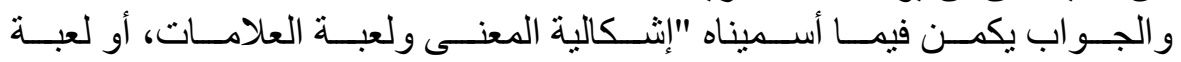

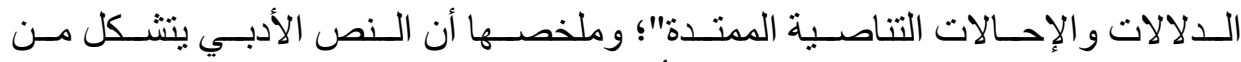

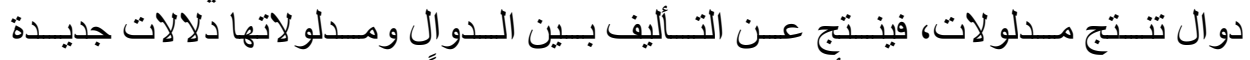

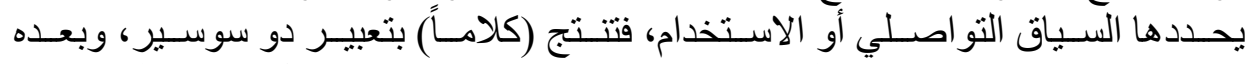

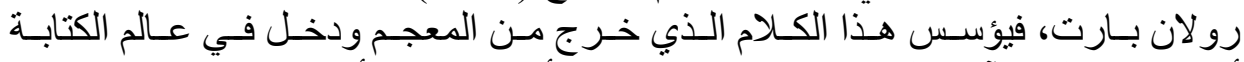

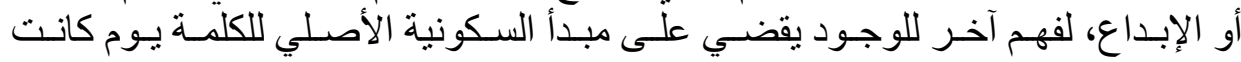

؛ جان كوهين، بنية اللغة الثعرية، ترجمة محمد الولي ومحمد العمري، المغرب، دار توبقال تودوروف، الثنعرية، ترجمة شكري المبخوت ورجاء بن سلامة، المغرب، دار.

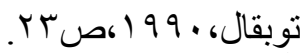
" انظر : ياكبسون،قضانيا الثعرية، ترجمة محمد الولي ومبارك حنوز، المغرب،دار توبقال 


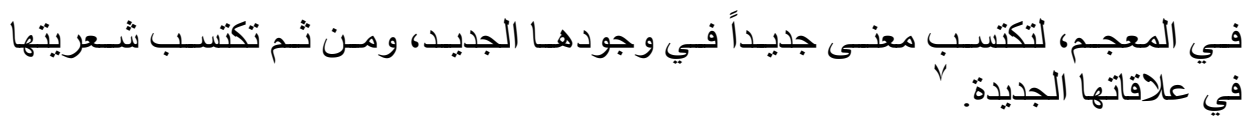

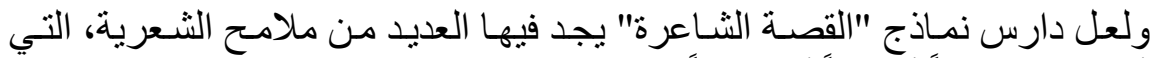

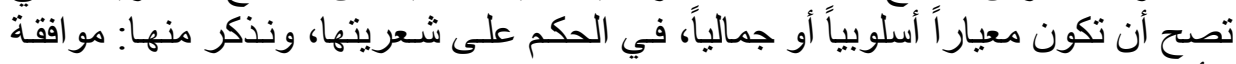

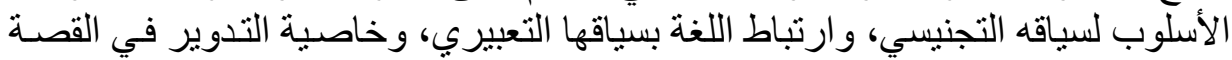
الثناعرة.

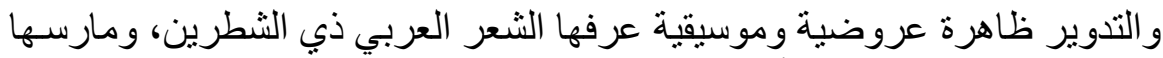

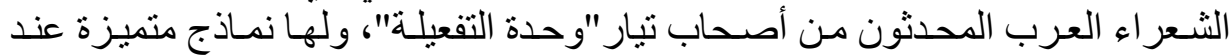

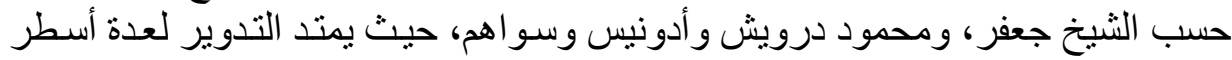

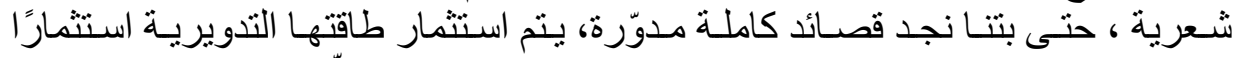

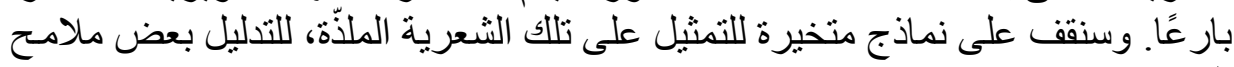
الثعرية : بارعًا

$$
\text { (1) نموذنة }
$$

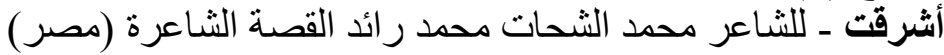

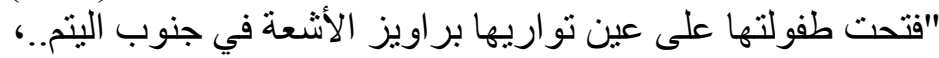

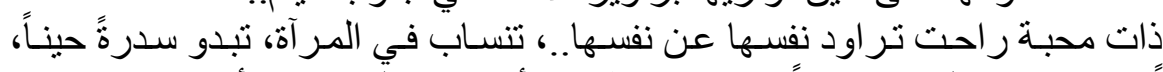

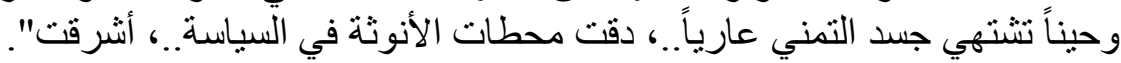

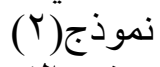

$$
\text { حضن الزمان/ ليانا الرفاعي (الأردن) }
$$

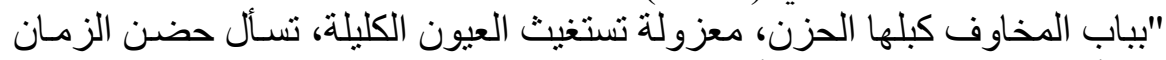

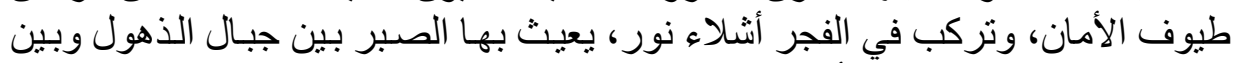

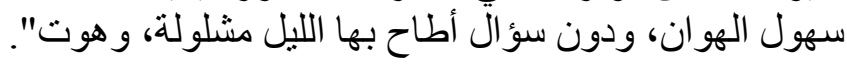

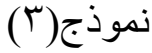

$$
\text { حنين/ مصطفى مطر (فلسطين) }
$$

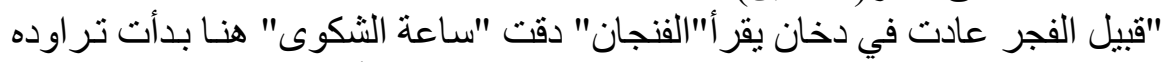

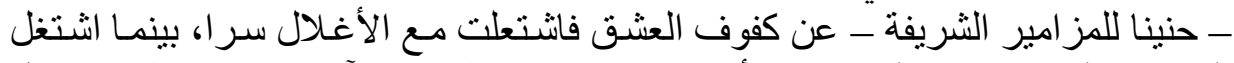

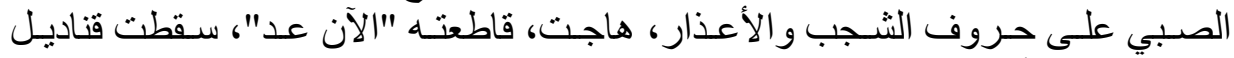
الخليل فقرر الأقصى مناهج سدرة الذكرى".

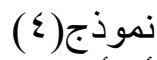

$$
\text { أنا أمهل/جمعد طكو (سوريا) }
$$

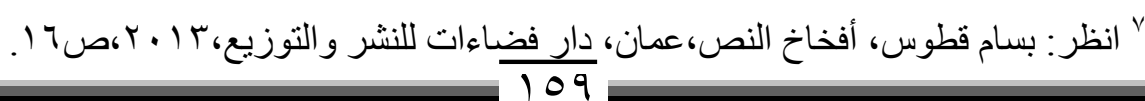


"راحت تفتش في حقيبتها القديمة عن بقايـا وردة ..كانت على منديل طفل ذات يوم

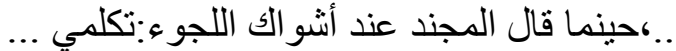

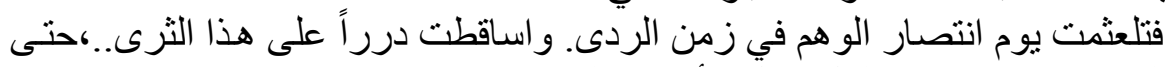

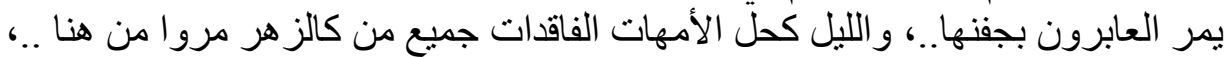

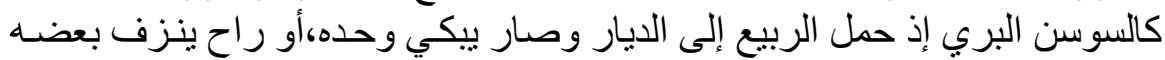

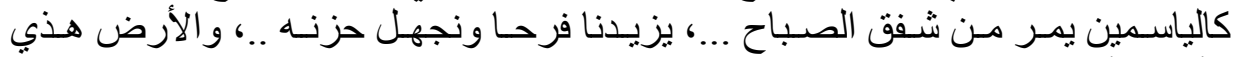

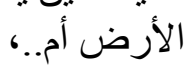

عندما ترك الجنود قميص طفل قد تلطخ بالدماء وكان صدقا ما رأت .

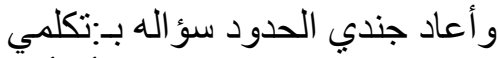

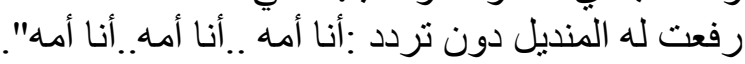

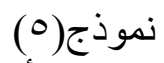

بيان/ د. أحلام عبد الهه الحسن (البحرين)

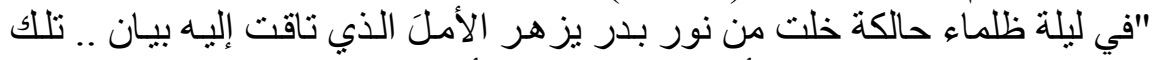

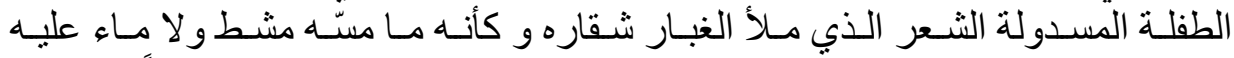

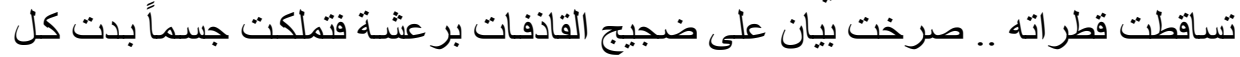

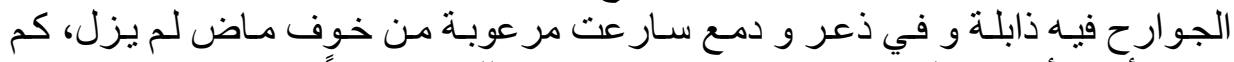

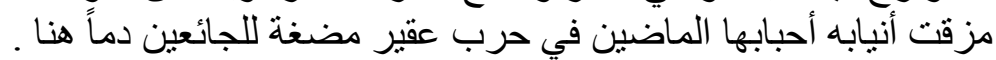

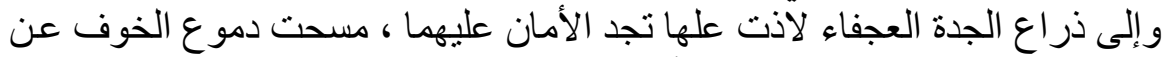

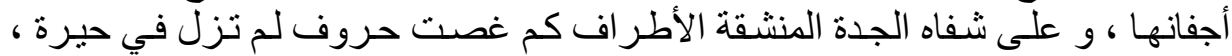
فتمالكت أعصابها و وليها

$$
\begin{aligned}
& \text { قالت : بيان بنيتي فلتهدئي .. }
\end{aligned}
$$

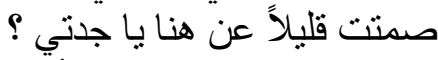

$$
\begin{aligned}
& \text { وببسمة تخفي المزيد من الأسىى } \\
& \text { نطقتُ : } \\
& \text { قريباً يا بيان صغيرتي : في } \\
& \text { في لوعة محزونة بان بن } \\
& \text { قالت : }
\end{aligned}
$$

لماذا هذه الحرب التي أخذت أبي ، و أخي ولم تترك سوى (جثنا) تر امت ها هنا ؟

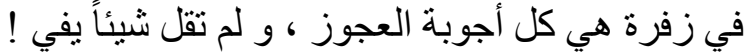

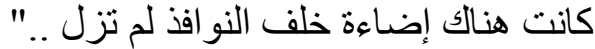




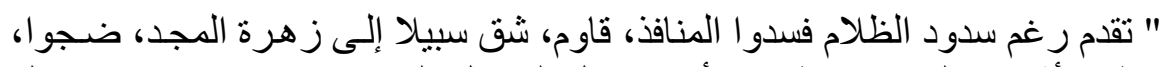

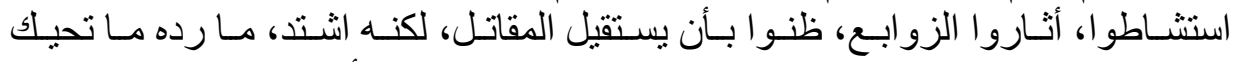

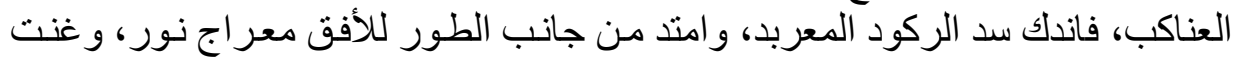

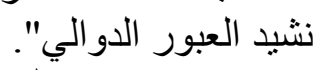

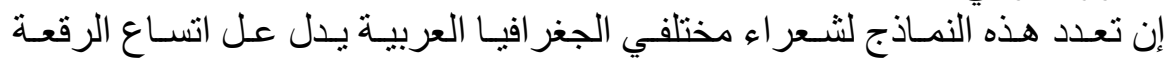

$$
\text { الزمانية و المكانية. }
$$

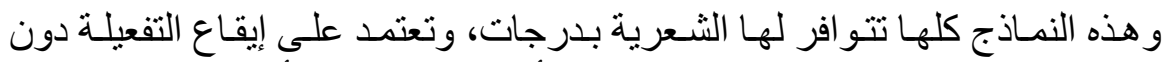

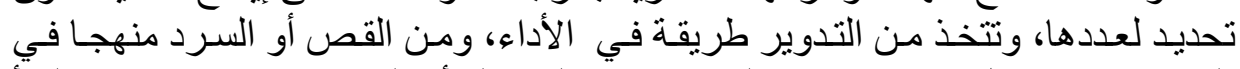

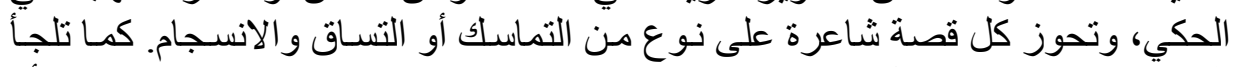

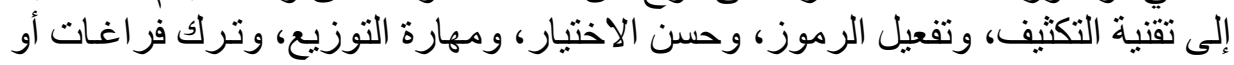

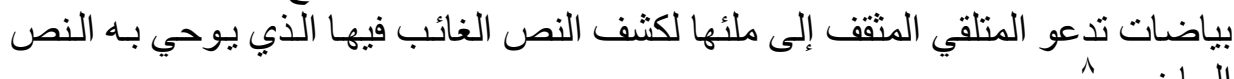

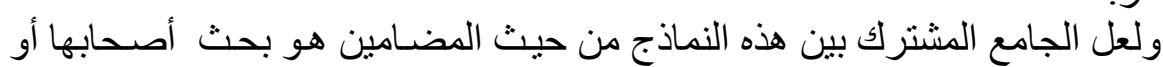

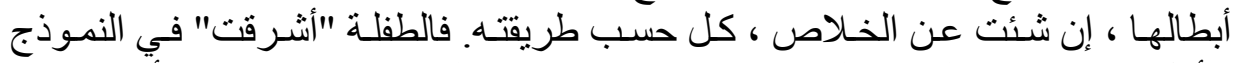

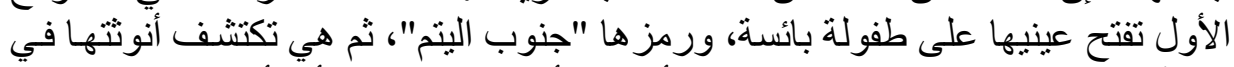

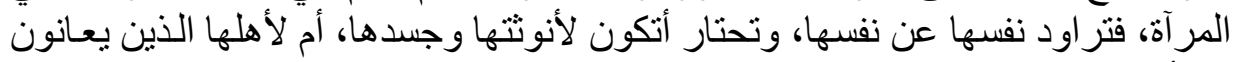

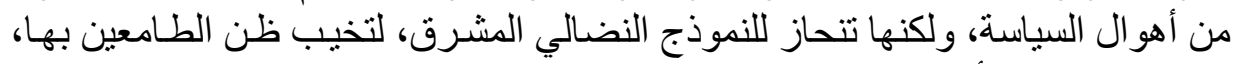

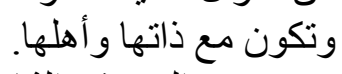

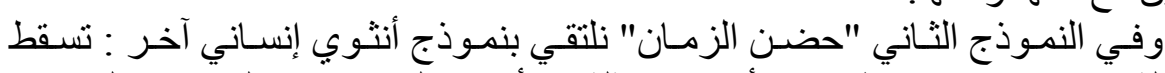

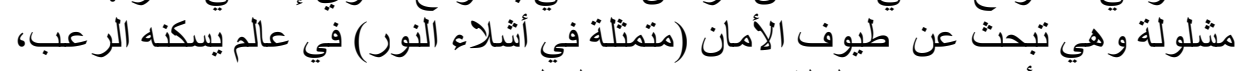

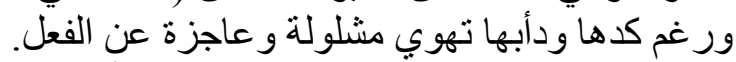

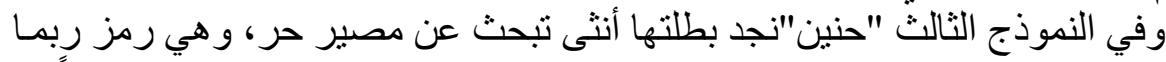

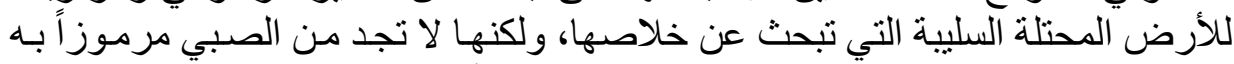

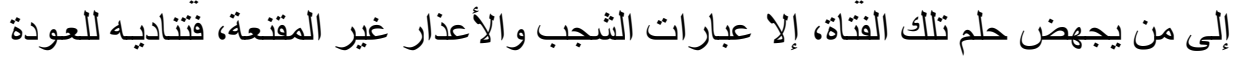

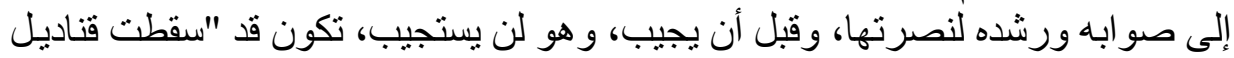

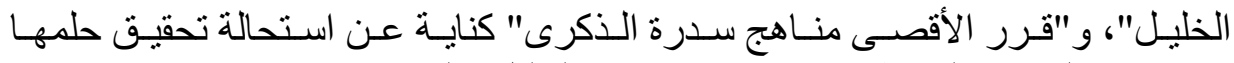

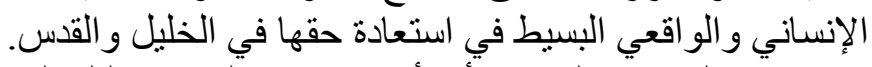

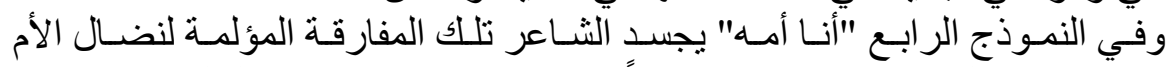

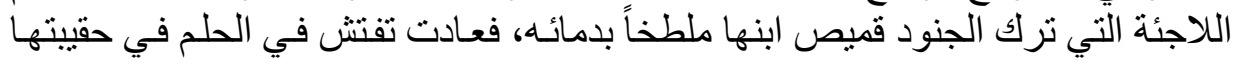

^ انظر: قطوس، علائق الحضور والغياب في شتاء ريتا الطويل، ومحمد عجور، القورة، القصة

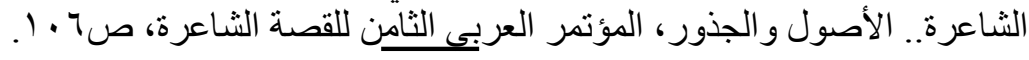




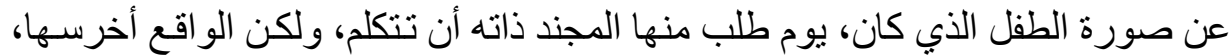

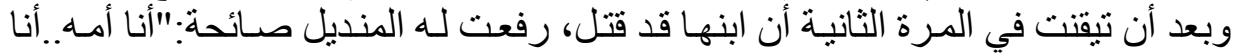

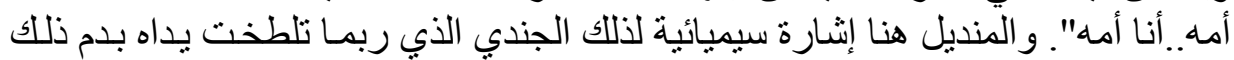
الطفل الذي فقدته أمه في اللجوء أناءئ

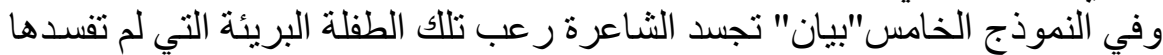

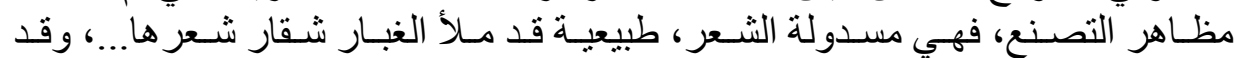

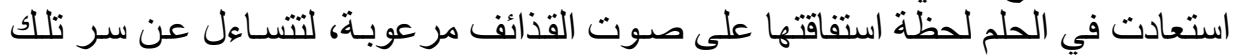

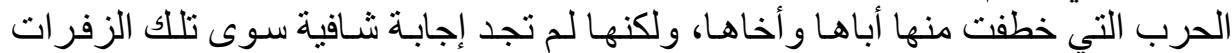

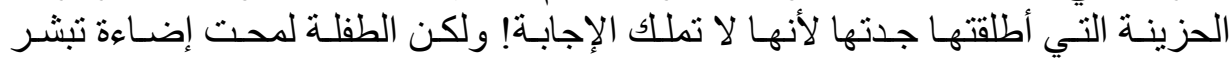

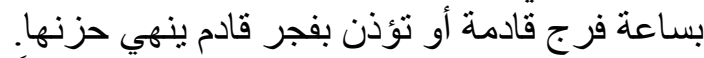

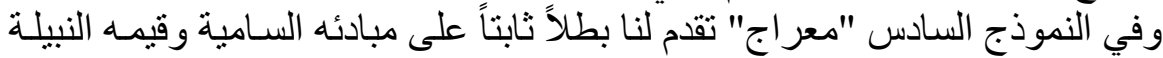

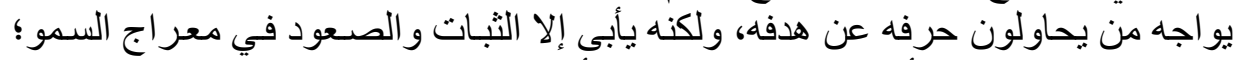

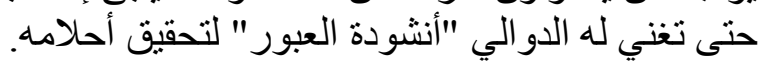

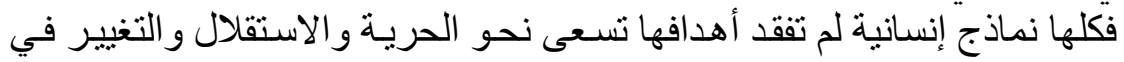

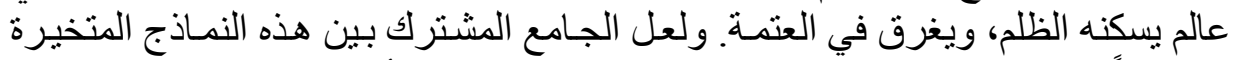

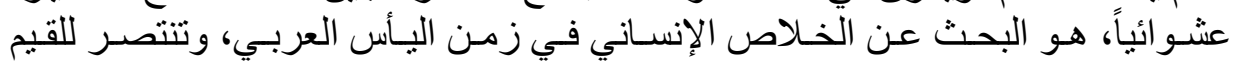
الإيتيقية، والخير، والخو والجمال.

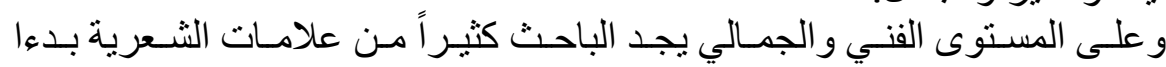

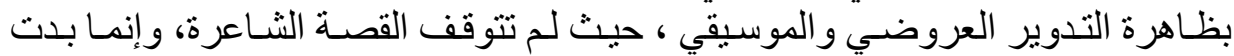

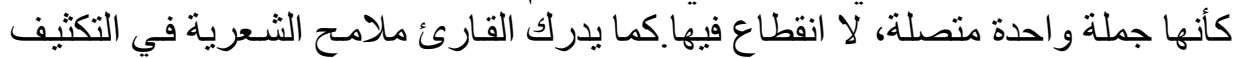

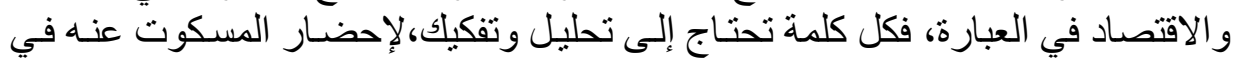

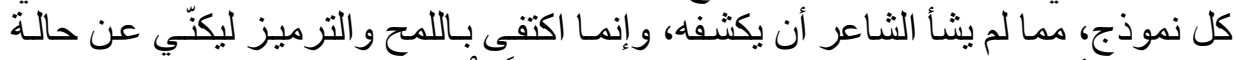

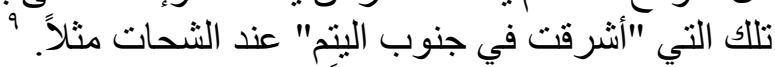

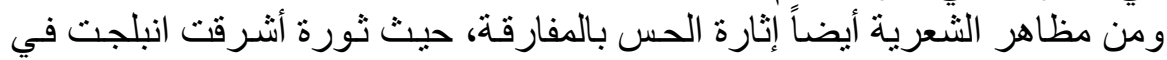

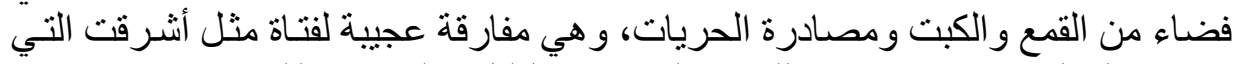

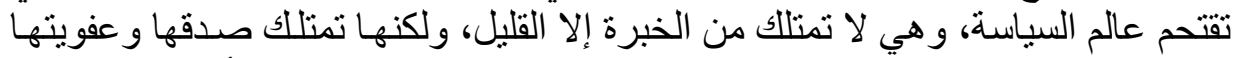

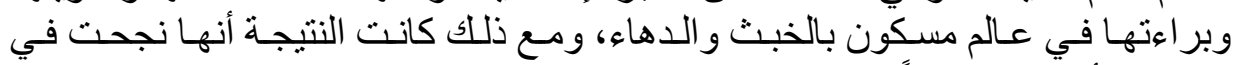

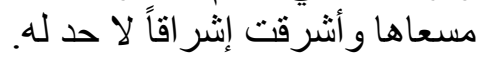

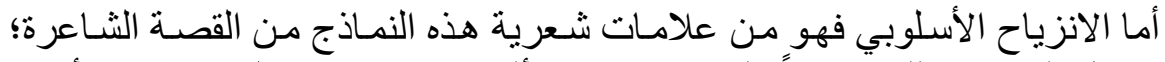

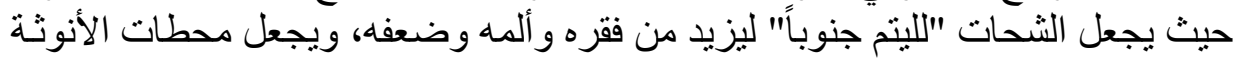
9 انظر: ربيحة الرفاعي، القصة الثاعرة ومعادلة تجديد الإبداع، في كتاب المؤتمر العربي

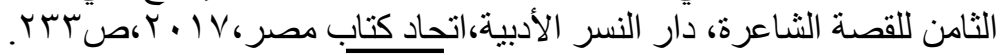
$17 T$ 


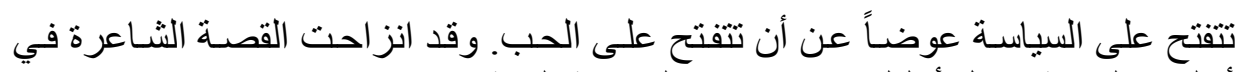

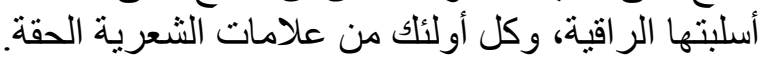

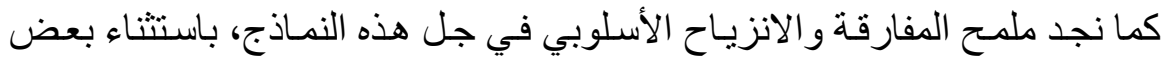

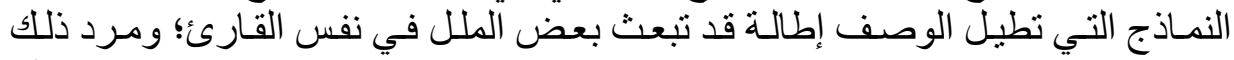

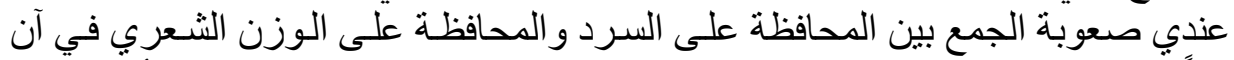

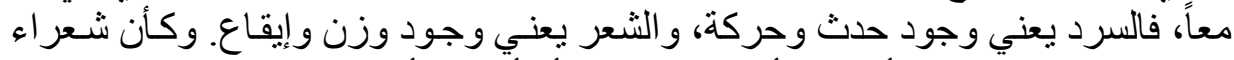

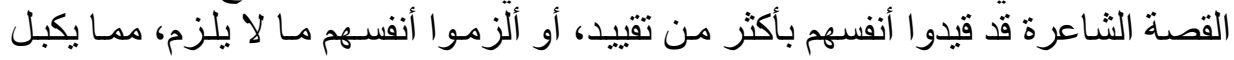

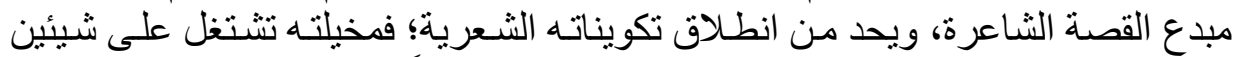

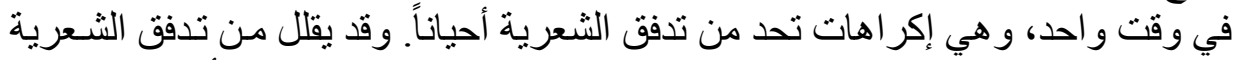

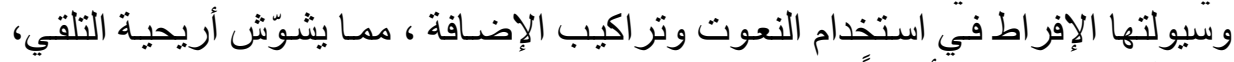

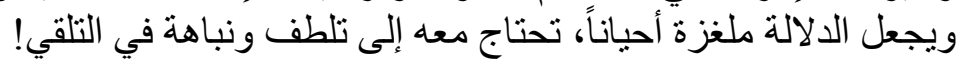

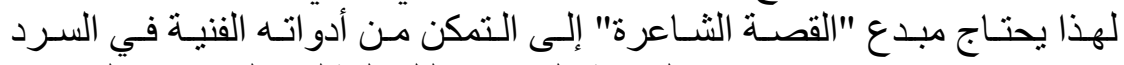

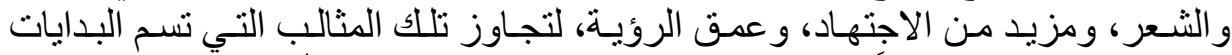

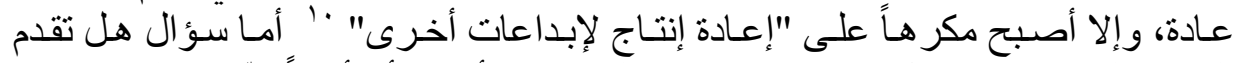

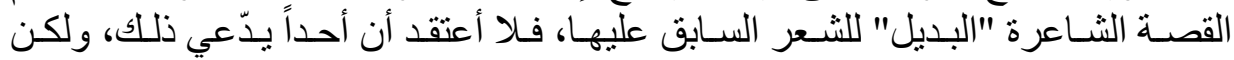

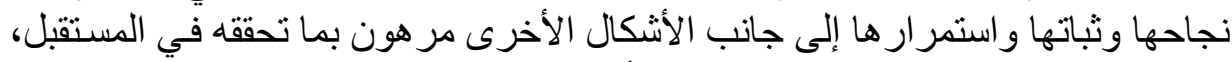
وما تجريه على بنيتها من تطوير ! وحسبها أنها تقدم الدليل على الألى وجودها.

. انظر:مصطفى عطية جمعة،جمالبات القصة الثاعرة الرؤية الطرح، البنية،الأسلوب، 


\section{مصادر البحث ومراجعه:}

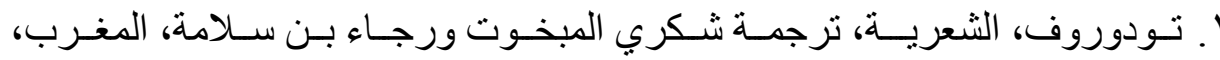

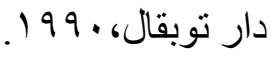

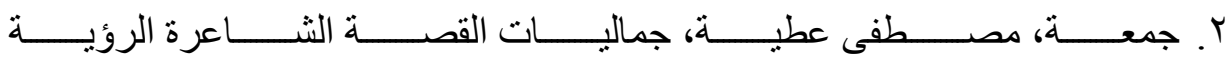

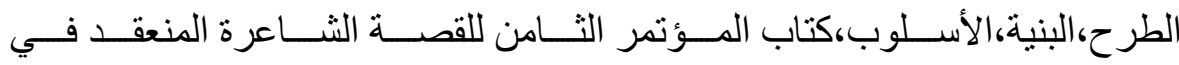

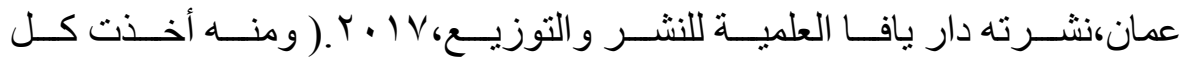
النماذج المدروسة للقصة الثاعرة).

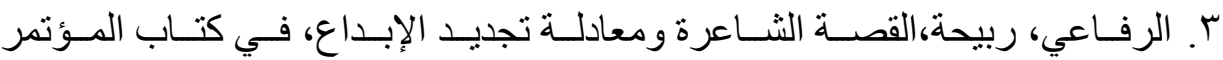

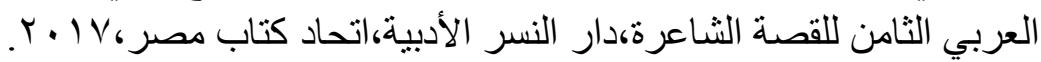

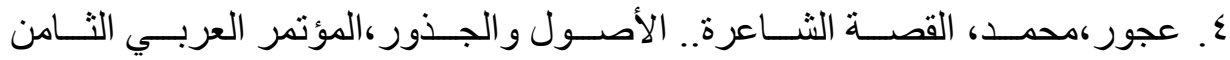

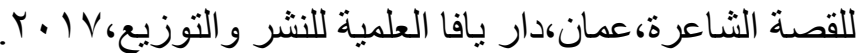

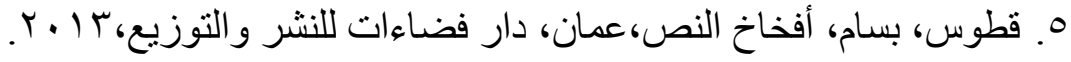

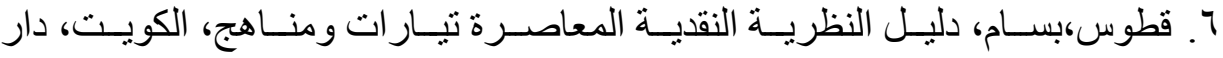

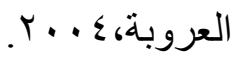

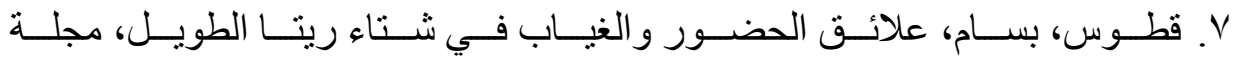

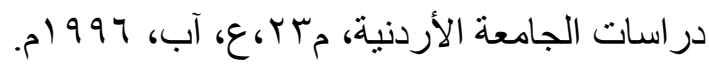

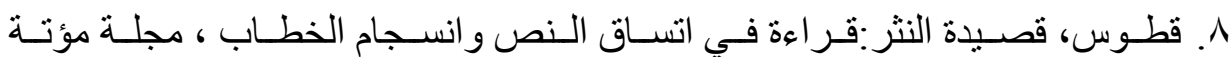

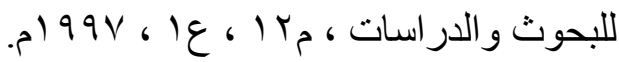

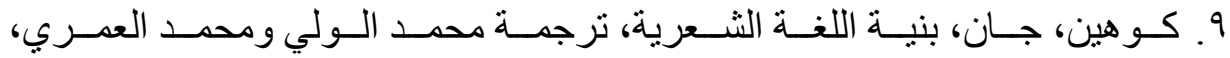

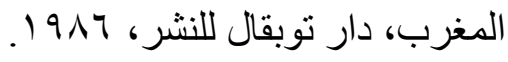

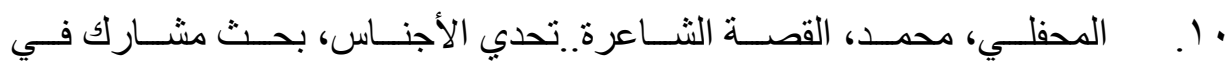

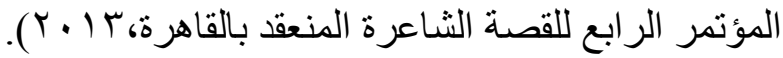

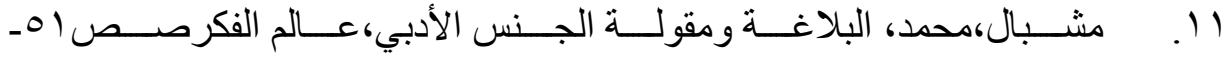

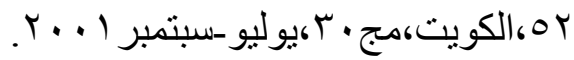

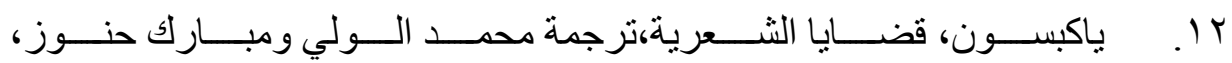

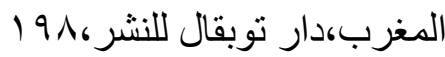

